\title{
Placental changes caused by food restriction during early pregnancy in mice are reversible
}

\author{
Jennifer L Harper ${ }^{1,2}$, Gerialisa A Caesar ${ }^{1,2}$, Kathleen A Pennington ${ }^{1}$, J Wade Davis ${ }^{3}$ \\ and Laura Clamon Schulz ${ }^{1,2}$ \\ ${ }^{1}$ Department of Obstetrics, Gynecology and Women's Health, NW509 Health Sciences Center, \\ ${ }^{2}$ Division of Biological Sciences and ${ }^{3}$ Department of Statistics, Department of Health Management and \\ Informatics, University of Missouri, 1 Hospital Drive, Columbia, Missouri 65212, USA \\ Correspondence should be addressed to L C Schulz; Email: schulzL@missouri.edu
}

\begin{abstract}
In a previous study, $50 \%$ calorie restriction in mice from d1.5 to 11.5 of pregnancy resulted in reduced placental weights and areas, relativel sparing of labyrinth zone area compared to junctional zone area, and dramatic changes in global gene expression profiles. However, little lasting effect was seen on adult offspring of these pregnancies, with a slight reduction in adiposity in males and some changes in liver gene expression in both sexes. The goals of the present study were to determine whether the placental changes induced by caloric restriction in early pregnancy had permanent, irreversible effects on the placenta, and whether the changes in liver gene expression in adult offspring were present before birth. There were no differences in placental weights or areas, or the areas of individual placental zones near term in mice that had previously been food restricted. Global gene expression profiles at d18.5 were indistinguishable in placentas from control and previously food-restricted mothers. In fetuses from restricted dams at d18.5, liver expression of $G c k$, a key regulator of glycogen synthesis, was reduced, whereas its expression was increased in livers from adult offspring of restricted dams. Ppara expression was also reduced in fetal livers from restricted dams at d18.5, but not in adult offspring livers. We conclude that alterations in the placenta caused by nutrient restriction in early pregnancy are reversible, and that alterations in gene expression in livers of adult offspring are not a result of changes initiated during pregnancy and maintained through adulthood.

Reproduction (2015) 150 165-172
\end{abstract}

\section{Introduction}

The Developmental Origins of Health and Disease field has shown that nutritional insults during pregnancy can have lasting consequences for the health of offspring. The timing of the insult is critical. In the seminal Dutch Hunger Winter studies, severe maternal food restriction during early pregnancy had the most deleterious consequences for offspring in later life, including higher rates of obesity, diabetes and cardiovascular disease (Ravelli 1976, Painter 2005). In contrast, those exposed in mid-gestation had greater rates of obstructive airway disease and microalbuminuria, and those exposed in late gestation had only a slight reduction in glucose tolerance (Roseboom et al. 2006). Similarly, in the sheep, nutrient restriction from $\mathrm{d} 28$ to 78 of gestation led to heavier, fatter, and less glucose-tolerant offspring (Gardner et al. 2005, Ford et al. 2007). In rats, exposure to 50\% nutrient restriction during the first 10 days of pregnancy also led to increased weight gain and adiposity in offspring (Jones \& Friedman 1982, Jones et al. 1984, Anguita et al. 1993, Sardinha et al. 2006).
It has been proposed that food restriction during early gestation has these effects because it is a critical period for placental development, and the altered placenta could then continue to influence the fetus through the rest of gestation (Barker et al. 1990, Dandrea et al. 2001, Barker et al. 2010). Placental development is altered by maternal nutrient restriction in early gestation in ways that suggest compensatory adaptation to maintain consistent nutrient supplies to the fetus. For example, in ewes that are food-restricted during early gestation, and then returned to normal feeding in late pregnancy, overgrowth of the placenta is observed at term (Foote et al. 1959, Clarke et al. 1998, Dandrea et al. 2001). Similarly, term placental weights were increased in women who were exposed to the Dutch Hunger Winter during the first trimester of pregnancy (Lumey 1998).

We have previously shown that in the mouse, $50 \%$ food restriction from d1.5 to 11.5 of pregnancy results in changes in placental morphology and gene expression. Specifically, food restriction reduced the weight of the placenta, and the area of the junctional zone, while the 
area of the labyrinth zone, the part of the placenta responsible for nutrient exchange, was preserved. (Schulz et al. 2012). Similar placental adaptations were observed by others in mice restricted through gestational d16 (Sferruzzi-Perri et al. 2011). However, food restriction from d1.5 to 11.5 had only modest effects on mouse offspring (Pennington et al. 2012). As adults, their body weights, glucose tolerance, and response to a high-fat diet were not different than those of offspring from control pregnancies. Among males only, offspring of food-restricted mothers had slightly lower adiposity and greater bone strength than offspring of controls, and increases in Igf1 $r$ mRNA and 18s rRNA levels in the liver (Pennington et al. 2012).

The goal of the present study was to determine whether the adaptations observed in the placenta in response to maternal food restriction are permanent or reversible. After food restriction from pregnancy d1.5 to 11.5 , dams were returned to ad libitum feeding until near term. We examined placental morphology and gene expression on $\mathrm{d} 18.5$ in order to identify lasting effects in the placenta. We also compared expression of key metabolic genes in fetal livers to determine whether differences previously noted in livers of the adult offspring begin prenatally.

\section{Materials and methods}

\section{Animals}

All animal procedures were approved by the University of Missouri Animal Care and Use Committee. Female Swiss Webster (ND4) mice, age 6-8 weeks, $\geq 25$ g, were obtained from Harlan Laboratories (Indianapolis, IN, USA) or born at the University of Missouri to Swiss Webster mice obtained from Harlan, and individually housed at the University of Missouri. Mice were acclimated for 1 week to AIN-93G diet for pregnancy and lactation (Research Diets, New Brunswick, NJ, USA) in a powdered, blue-dyed form presented in specialized dishes for weighing (Townsend et al. 2008). Average daily individual food consumption levels were estimated by weighing food every other day for 10-14 days. Females were introduced to male cages, and the day in which a copulatory plug was detected was considered pregnancy d0.5. Females were returned to individual cages, and at $\mathrm{d} 1.5$ randomly assigned to one of two treatment groups: i) ad libitum fed plus saline injection (control) or ii) food-restricted to $50 \%$ of prior consumption levels plus saline injection (restricted). Saline injections were given to permit comparisons to our previous studies, in which we examined placentas at d11.5 and offspring during adulthood using the same two treatment groups (Pennington et al. 2012, Schulz et al. 2012). In those studies, saline injections were used to control for leptin injections given to a third treatment group, which was not included in this study. Injections were given intraperitoneally once daily at $1400 \mathrm{~h}$ and mice were fed at $1600 \mathrm{~h}$. All mice were fed ad libitum without injections from d11.5 to 18.5 , at which time they were euthanized by $\mathrm{CO}_{2}$ inhalation followed by cervical dislocation for collection of blood, placentas, and fetuses.

\section{Placental morphology}

After weighing, half of the total number of placentas from each dam were fixed overnight in $4 \%$ paraformaldehyde, then dehydrated and paraffin embedded (IDEXX/RADIL, Columbia, MO, USA). Each placenta was bisected mid-sagitally and embedded cut-face down. Three pairs of serial $5 \mu \mathrm{m}$ sections were cut at $50 \mu \mathrm{m}$ intervals and stained with hematoxylin and eosin (H\&E). The largest face on each slide was chosen for morphological analysis. Overlapping images were photographed with a $4 \times$ objective lens on an Olympus $\mathrm{I} \times 81$ microscope and assembled into a single, high-resolution image covering the entire placental cross-section. Total cross-sectional area, junctional zone, and labyrinth zone areas were measured by manual outlining using the freehand selection tool in ImageJ Software (National Institutes of Health, Bethesda, MD, USA) while blinded to treatment group. Cross-sectional measurements were averaged from three placentas per dam to obtain $n=1$ (total $n=8$ control, $n=8$ restricted). For comparison of placental blood spaces, maternal blood sinuses and fetal blood vessels within the labyrinth were identified in H\&E stained sections by the appearance of nucleated (fetal) and enucleated (maternal) red blood cells, as well as the location of fetal endothelial cells and trophoblast, and manually outlined with the freehand selection tool within Image Software, also while blinded to treatment group. Five frames were photographed per placenta with a $40 \times$ objective, and 2-3 placentas were analyzed per dam to obtain $n=1$ (total $n=7$ per treatment group).

\section{Leptin and insulin measurement}

Terminal blood samples from dams were collected by cardiac puncture at d18.5. Serum was obtained by centrifugation of blood samples at $1000 \mathrm{~g}$ for $12 \mathrm{~min}$. Leptin and insulin were measured by commercial sandwich ELISA (Millipore, Billerica, MA, USA).

\section{Statistical analysis}

Dams were considered the experimental unit such that fetal weights, placental weights, and placental areas were averaged within each dam to obtain $n=1$. Student's $t$-tests were used to compare means, and $F$-test to compare variances between control and restricted dams.

\section{Microarray analysis}

Half of the total number of placentas from each dam were cut in two, and one piece was frozen in TriReagent (Sigma). Following homogenization and phase separation according to TriReagent instructions, the aqueous phase was further purified using RNEasy Mini kit (Qiagen). Microarray analysis was conducted on placentas from five dams from each of the two treatment groups. RNA from two placentas was pooled to obtain one sample for each dam. Preparation of cRNA, microarray hybridization, and scanning and cluster analysis were carried out by GenUs Biosystems (Northbrook, IL, USA). Mouse $4 \times 44$ whole genome arrays (Agilent, Santa Clara, CA, USA, Design ID 026655) containing over 39000 probes were scanned on an Agilent 
G2565 Microarray Scanner. Data were analyzed with Agilent Feature Extraction, GeneSpring GX v7.3.1, and R 3.0.1 Software.

The primary analysis of microarray gene expression data was conducted using the Linear Models for Microarray Data (limma) package (Gentleman et al. 2005) and the Agi $4 \times 44$ PreProcess package available through the Bioconductor project (Gentleman et al. 2004) for use with R Statistical Software (R Foundation for Statistical Computing, Vienna, Austria). Data quality was examined via an extensive battery of metrics obtained using the Agi $4 \times 44$ PreProcess package. Foreground mean signal was used with background median signal for background correction in order to produce positive corrected intensities via the normexp function in limma. Between-array normalization was done via quantile normalization (Bolstad etal. 2003). Because Agilent $4 \times$ 44 chips contain up to ten replicated (non-control) probes for a given set, these were collapsed into a single value by computing the median of the probes intensities belonging to the same set. Finally, independent filtering was carried out on probe sets that were not putatively expressed across the sample (as defined by $\log 2$ mean signal intensity $>8$ ); these were excluded $(n=26881)$ from further statistical analyses in order to reduce false positives, as they contain very little information content relative to the analysis at hand and doing so increases power (Bourgon et al. 2010).

After this preprocessing was completed, the statistical analysis was performed using an empirical Bayesian moderated t-test (Smyth 2004) applied to normalized intensity for each gene ( $n=11608$ remaining after pre processing), where the restricted group was compared to the control group. The comparisons are expressed as fold changes (res/ctl) along with adjusted $P$ values. Adjustment to the $P$ values was made to account for multiple testing using the false discovery rate (FDR) method of Benjamini and Hochberg. We chose $10 \%$ as our FDR cutoff for declaring statistical significance.

\section{Fetal liver gene expression}

Liver samples were collected from each of the d18.5 fetuses, placed in TRI Reagent (Sigma), and stored at $-80{ }^{\circ} \mathrm{C}$ until further use. Samples were homogenized in Trireagent with an Omni GLH Homogenizer and centrifuged to remove excess polysaccharides. After phase separation, RNA was further purified by using the RNeasy isolation procedure (Qiagen) according to manufacturer's protocol for RNA cleanup. Genomic DNA was removed with TurboDNase (Ambion, Austin, TX, USA) according to manufacturer's protocol.

RNA was extracted from the liver of one female fetus each from five dams per treatment group and from one male fetus each from four dams per treatment group, and analyzed by custom $\mathrm{RT}^{2}$ Profiler PCR arrays (Qiagen) on an Applied Biosystems 7500 real-time PCR system (Applied Biosystems) using $\mathrm{RT}^{2}$ SYBR Green ROX qPCR master mix according to manufacturer's protocol, as previously described (Pennington et al. 2012). For the PCR arrays, $1 \mu \mathrm{g}$ of total RNA was reverse transcribed using the $\mathrm{RT}^{2}$ first strand kit(Qiagen). Three housekeeping genes, 18s rRNA (18s ribosomal RNA), Actb (actin- $\beta$ ), and Hprt (hypoxanthine phosphoribosyltransferase 1) were examined; however, due to variation in $18 \mathrm{~s}$ and Hprt, only $A c t b$ was used to calculate fold changes. Manufacturer's external reverse transcription and positive PCR controls were also included. Fold differences in expression were calculated according to the $\Delta \Delta C$ t method (Livak \& Schmittgen 2001).

Expression of two additional genes, $C d 36$ and Srebp1c was examined by real-time RT-PCR in fetal livers. There was some evidence of differentially susceptibility to non-alcoholic fatty liver disease (NAFLD) in offspring in our previous study (Pennington et al. 2012) and these genes have been implicated in NAFLD (Shimomura et al. 1999, Lemoine et al. 2006, Koonen et al. 2007, Anderson \& Borlak 2008, Greco et al. 2008). Additionally, their expression in offspring liver is altered in other developmental programming paradigms, such as maternal high fat/high sugar or low-carbohydrate feeding (Zhang et al. 2005, Bruce et al. 2009, Gregorio et al. 2010). Total RNA (500 ng) was reverse transcribed with SuperScript III reverse transcriptase (Invitrogen/Life Technologies), using random hexamer primers, according to manufacturer's protocol. Data were normalized to the average $C t$ of $A c t b$ and Gapdh. Expression of these control genes was first determined not to differ between control and restricted samples; for Actb, $C t$ values were $19.8+0.9$ for controls and $20.2+0.5$ for restricted; for Gapdh, Ct values were $21.3+0.9$ for controls and $21.1+0.6$ for restricted. Primer sequences were designed by using Primer Express Software (Applied Biosystems), synthesized by Integrated DNA Technologies (Coralville, IA, USA) and validated by performing serial dilutions of template cDNA. Primer sequences were Cd36 (5'-GGTCCTTACACTACAGAGTTCGTTA- $3^{\prime}$ and $5^{\prime}$-CATTGGGCTGTACAAAAGACACA-3') and Srebp1c (5'-TGGTGGGCACTGAAGCAAA-3' and (5'-TGGTGGGCACTGAAGCAAA- $3^{\prime}$ and $5^{\prime}$-GCAAGAAGCGGATGTAGTCGAT- $\left.3^{\prime}\right)$.

\section{Results}

\section{Maternal characteristics}

Whereas $90 \%$ of ad libitum (control) fed dams remained pregnant after initial detection of a copulatory plug, roughly one-third of pregnancies were lost in the restricted dams by $\mathrm{d} 18.5$, though this was not a statistically significant difference (Table 1). In addition,

Table 1 Pregnancy characteristics.

\begin{tabular}{lcc}
\hline Treatment group & Control & Restricted \\
\hline$n$ d0.5 & 10 & 16 \\
$n$ d18.5 & $8(1)$ & $9(2)$ \\
Pre-pregnancy weight $(\mathrm{g})$ & $27.5 \pm 0.3$ & $26.3 \pm 0.5$ \\
Maternal weight at d18.5 $(\mathrm{g})$ & $44.2 \pm 1.1$ & $42.9 \pm 4.2$ \\
Litter size at d18.5 & $10.8 \pm 0.7$ & $9.4 \pm 0.9$ \\
Maternal serum leptin & $13.9 \pm 3.2$ & $16.1 \pm 1.5$ \\
$\quad$ d18.5 (ng/ml) & & $1.56 \pm 0.39$ \\
Maternal serum insulin & $2.04 \pm 0.39$ & \\
$\quad$ d18.5 (ng/ml) & & \\
\hline
\end{tabular}

$n \mathrm{~d} 0.5=$ number of mice assigned to each group with copulatory plugs $n$ d18.5 = number of mice from which placental and fetal tissues were collected at d18.5. Number in parenthesis indicates number of mice that delivered prior to $\mathrm{d} 18.5$. The remaining mice were no longer pregnant at d18.5. There were no significant differences between groups. 

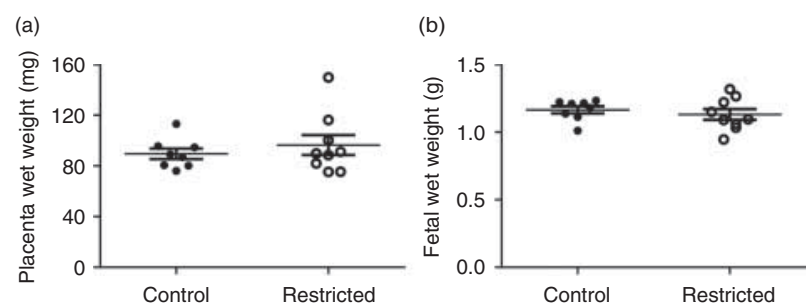

Figure 1 (a) Placental wet weights at d18.5. Neither means nor variances $(P=0.08)$ were significantly different. (b) Fetal weights at d18.5. There was no significant difference. Each marker represents the mean for one litter. Lines represent the treatment group mean, and bars show S.E.M.

one mouse in the control group and two mice in the restricted group gave birth prior to $\mathrm{d} 18.5$, and no fetal or placental tissues could be collected. There were no differences between treatment groups in maternal serum leptin or insulin concentrations at the time of sacrifice, or in maternal weights (Table 1). Thus, maternal characteristics recovered completely in the 1 -week following return to ad libitum feeding.

\section{Placental and fetal weights}

There were no differences in litter sizes between control and restricted dams at d18.5 (Table 1). There also were no significant differences in mean fetal or placental weights (Fig. 1), or the ratio of fetal:placental weights, a measure of placental efficiency (not shown). When fetal and placental weights were separated by fetal sex, there were still no differences between treatment groups (data not shown).

\section{Placental morphology}

There were no differences in total cross-sectional area of the placenta or cross-sectional areas of the junctional or labyrinth zones between control and previously food restricted dams (Fig. 2). The cross-sectional areas of the maternal blood sinuses and the fetal blood vessels within the labyrinth zone were also examined and found not to differ significantly between treatment groups (Fig. 3).

\section{Placental gene expression}

Microarray analysis was conducted on pooled RNA from two placentas each from five dams in each of the treatment groups. Both heat map and scatter plot visualization of array data reveal highly similar patterns of gene expression between control and restricted placentas at d18.5 (Fig. 4). Using a 10\% FDR cutoff, there were no differentially expressed genes between placentas of control and restricted dams. The 50 genes showing the highest probability of differential expression are listed in Supplementary Table 1, see section on supplementary data given at the end of this article. The smallest adjusted $P$ value was 0.41 .

\section{Fetal liver}

Fetal liver gene expression was compared between offspring groups by using the same real-time PCR arrays previously used to identify differences in the adult offspring from these treatments (Pennington et al. 2012). Expression of genes encoding two key fatty acid transporters, $C d 36$ and Srepb1c were also examined by real-time PCR in these samples. Ppara expression was significantly lower in livers of fetuses from restricted dams overall, although when the sexes were analyzed separately, the difference was only significant within male offspring (Fig. 4). Expression of Gck was significantly reduced in fetal livers regardless of sex, although when the sexes were analyzed separately, the difference was only significant within females (Fig. 5).

\section{Discussion}

When mice were placed on $50 \%$ food restriction from d1.5 to 11.5 of pregnancy, they had significantly reduced placental weights, placental junctional zone areas, and junctional to labyrinth zone ratios, along with somewhat reduced fetal blood space areas within the labyrinth
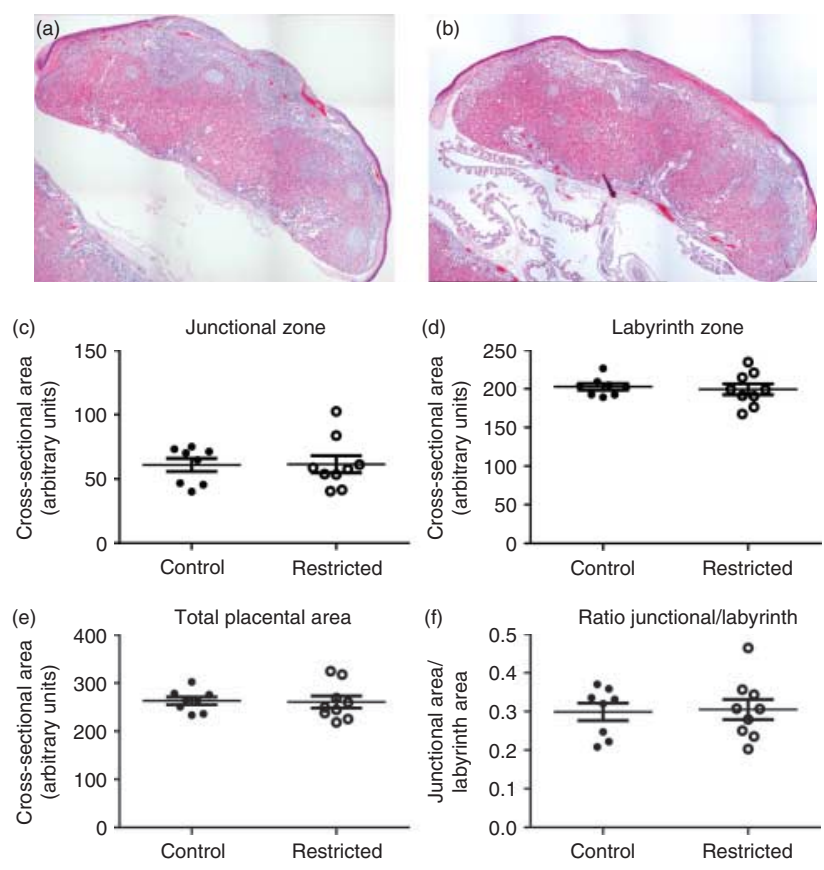

Figure 2 Representative composite images of placentas from (a) control and (b) previously restricted dams at pregnancy d18.5. Cross-sectional areas of the (c) junctional zone, (d) labyrinth zone, (e) total crosssectional area, and ( $f$ ) the ratio of the junctional zone/labyrinth zone areas were not different between control and restricted dams. Each marker represents the mean from one litter. Horizontal lines are the means for each maternal treatment group, and bars represent S.E.M. 
(a)
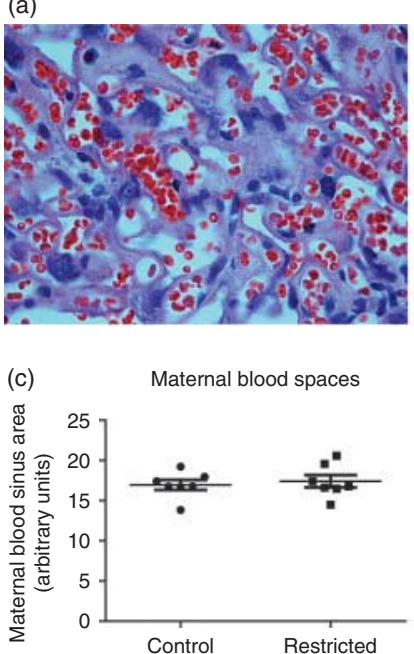

(b)
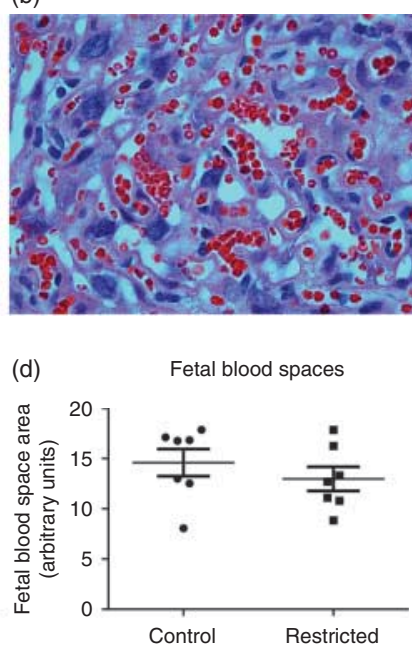

Figure 3 Representative images of labyrinth zone photographed with a $40 \times$ objective lens from (a) control and (b) previously food-restricted dams. There were no differences in cross-sectional areas of (c) maternal or (d) fetal blood spaces. Each marker represents the mean from one litter. Horizontal lines are the means for each maternal treatment group, and bars represent S.E.M.

zone (Schulz et al. 2012) at d11.5. Over 200 gene expression differences were identified by microarray, including PCR-confirmed decreases in Ceacam12, Gbp1 and Tpbpa. However, the adult offspring of these pregnancies had largely normal metabolism, so here we asked whether the placental abnormalities observed at d11.5 were sustained until late pregnancy. The answer is no; we detected no significant differences in placental weights, morphology or gene expression at d18.5 in mice that had been food restricted from d1.5 to 11.5 when compared to controls.

This finding is consistent with the hypothesis that lasting changes in the placenta are responsible for lasting changes in offspring physiology that follow early pregnancy insults. In humans and sheep, early pregnancy nutrient restriction that led to obesity in offspring also led to oversized placentas at term. We found that in the mouse, early pregnancy nutrition did not lead to placental abnormalities at term and did not lead to offspring obesity. Thus, recovery of normal placental morphology and gene expression may underlie species differences in the effects of early pregnancy undernutrition on adult phenotype. As a caveat, only one strain of outbred mouse was used, so this conclusion may not be applicable to all mice. For example, strain differences in remodeling of the placental vasculature have been documented between inbred $\mathrm{C} 57 \mathrm{Bl} / 6$ and outbred CD1 mice (Rennie et al. 2012).

The ability of the mice to recover normal placental function and yet not overcompensate by term following early pregnancy food restriction may be a function of timing. The timescales for development in the sheep and human are much longer than in the mouse, leaving more time for compensation to become overcompensation. On the other hand, the rat has only a 1-2 days longer gestation period than the mouse, and food restriction during early gestation can lead to offspring obesity in rats. In a series of studies, Jones and Friedman found that male rat offspring became obese following $50 \%$ maternal food restriction from d1 to 10, and Palou et al. (2010) saw a similar effect in offspring of rats with just $20 \%$ food restriction.

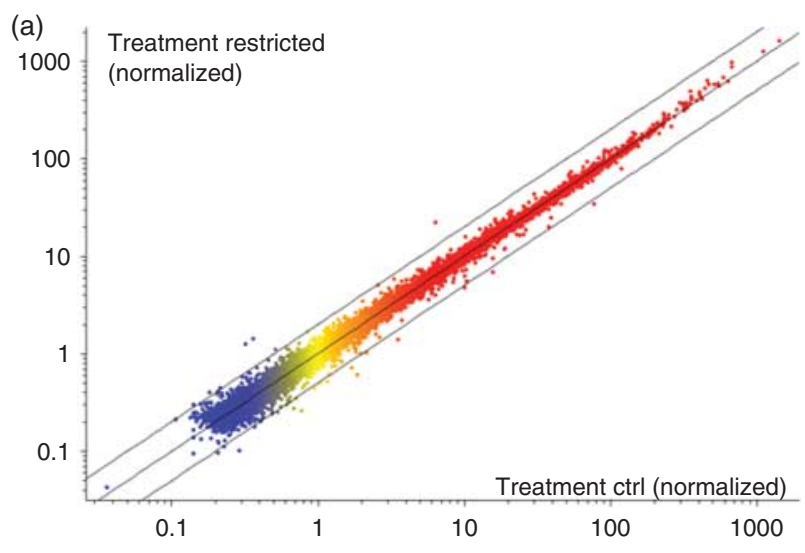

(b) Heat map of control and restricted samples

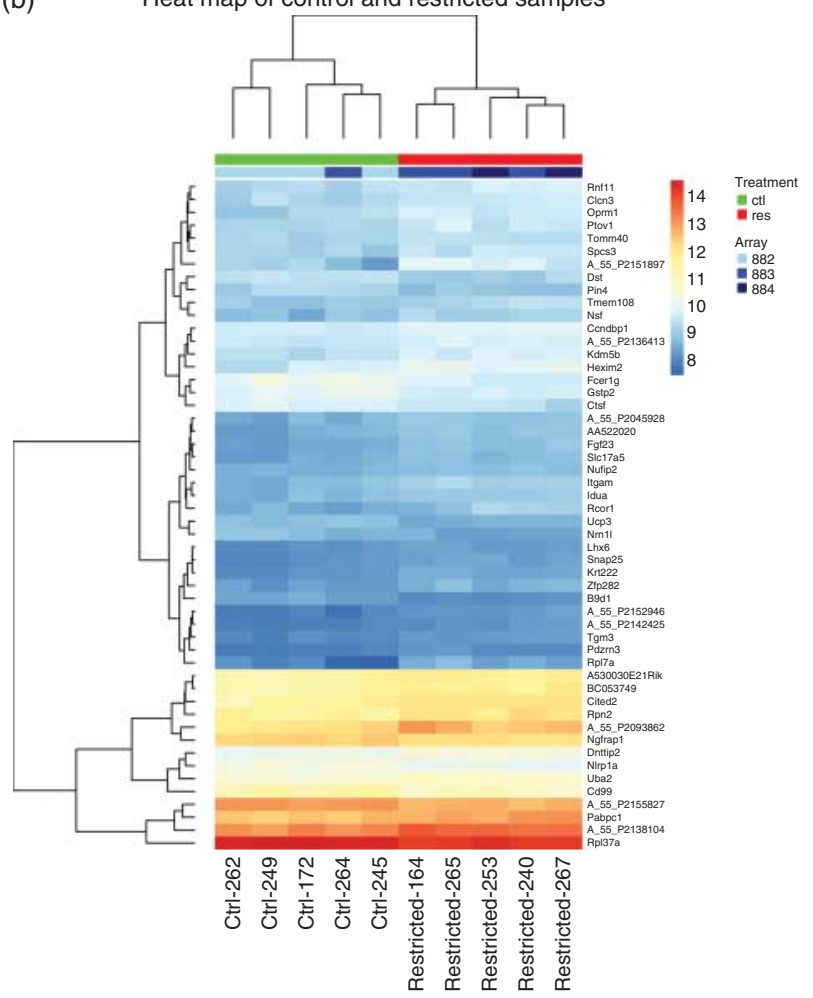

Figure 4 Whole genome microarray analysis of five pairs of placentas from control and food-restricted dams. (a) Scatter plot: genes present (above background) in all replicates of at least one treatment (15 430 probes) are displayed as normalized to the 75 th percentile of each array. Red, high expression; Yellow, medium expression; Blue, low expression; Center line, identical expression; outer lines, twofold difference. (b) Heat map based on 50 genes most likely to be differentially expressed. No significant differences in expression were found. 


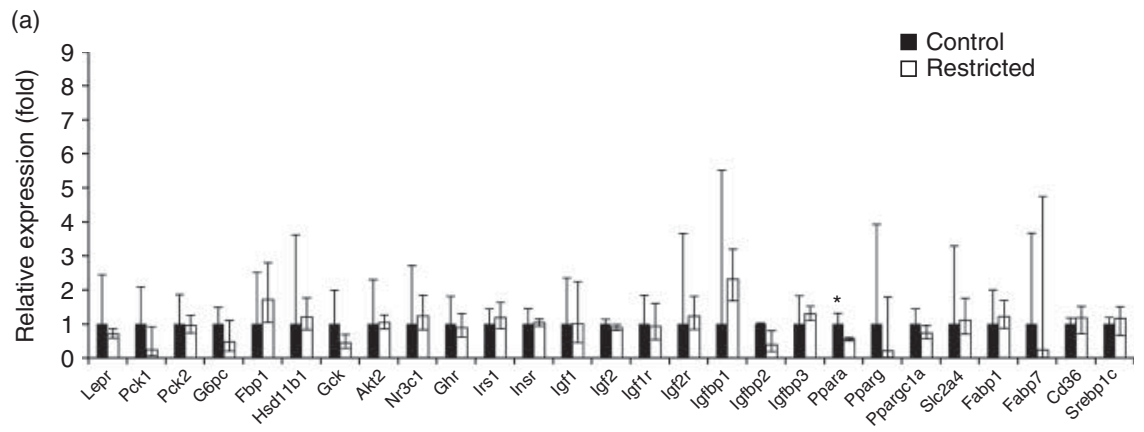

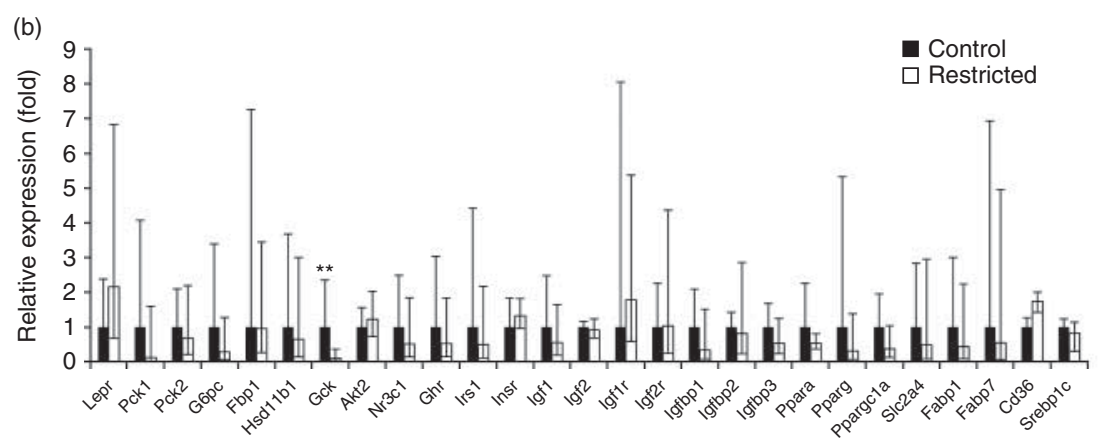

Figure 5 Relative expression of key metabolic genes in the liver of (a) male and (b) female fetuses from control (black) and restricted (white) dams determined by real-time PCR. Each is expressed as fold-change relative to control sample mean. Error bars indicated fold-changes calculated from mean \pm s.D. of $\Delta \Delta C$ t. $* P=0.04, * * P=0.01$.
In contrast, Anguita et al. (1993) found that female rat offspring became obese following $50 \%$ maternal food restriction from $\mathrm{d} 1$ to 14 , but male offspring weighed less than offspring of controls. All of these studies initiated food restriction on the morning following mating, whereas our food restriction began on the next day, which may also explain the differing long-term consequences. The periconceptual period is critical for some developmental programming effects, particularly that of dietary methyl donors (Sinclair et al. 2007). The effects on offspring of total caloric restriction during the period prior to $\mathrm{d} 1.5$ mouse pregnancy remains to be tested.

There were two differences in gene expression in fetal livers at d18.5 from previously food-restricted dams. In the fetal livers from restricted dams, Gck mRNA was reduced nearly tenfold. Gck encodes glucokinase, the enzyme that converts glucose to glucose-6-phosphate in the first step of glycolysis. In both humans and mice, loss-of-function mutations in Gck are associated with mature onset diabetes of the young and reduced birth weights, likely due to its role in glucose sensing and insulin release in the pancreas (Terauchi et al. 2000, Shields et al. 2010). In the liver, Gck regulates glycogen synthesis, but fetuses depend largely on other hexokinases for this function (Cifuentes et al. 2008), and mice with Gck knockout in liver do not develop abnormal blood glucose until after weaning (Wang et al. 2013). Thus, the significance of this dramatic expression difference for fetal physiology is not clear. Gck expression and methylation have previously been shown to be altered in adult rats following prenatal exposure to BPA (Ma et al. 2013), suggesting it is a target of fetal programming. However, the decreased expression we observed in fetal livers from restricted dams was not present in female offspring of restricted dams at 29 weeks of age (Pennington et al. 2012) and Gck expression was significantly increased in livers of adult males from restricted dams (Pennington et al. 2012). These changes in liver Gck expression suggest complex regulation by maternal undernutrition.

The other expression difference was a reduction in Ppara expression in the livers of fetuses from previously food-restricted mothers. Ppara, a member of the peroxisome proliferator-activated receptor family, is a key regulator of lipid metabolism in the liver. It is hypothesized to play a protective role in rat fetuses of dams with type I diabetes (Martinez 2010). A reduction in Ppara expression was also observed in the livers of adult rats that had been exposed to maternal undernutrition throughout pregnancy (Gluckman et al. 2007). However, the opposite effect, an increase in liver Ppara expression, was observed at postnatal $\mathrm{d} 6$ in rats born to dams fed a protein-restricted diet throughout pregnancy (Lillycrop et al. 2005). The decreased Ppara expression present in fetal livers from restricted dams was not detected in the adult offspring of restricted mothers at 29 weeks of age (Pennington et al. 2012). However, Ppara expression was only measured in the adult offspring following high-fat diet consumption. The high-fat diet eliminated the lower adiposity that male offspring displayed on a standard diet, so it may also have erased differences in Ppara expression (Pennington et al. 2012). A caveat to interpretation of either difference in liver gene expression is that it is not 
known whether these changes are reflected by changes in protein production.

A strength of the liver analyses was the separation of samples by fetal sex, as our previous study had shown differing effects of maternal treatment on male and female adult offspring (Pennington et al. 2012). Similarly, it was recently shown in the baboon that food restriction induced consistent changes in gene expression in female but not male placentas (Cox et al. 2013), and murine female placentas also respond more dramatically to high-fat diet changes (Mao et al. 2010). Thus, a drawback of the placental microarray analysis is that RNA from two placentas was pooled at random from each dam, so that results cannot be separated by sex. Treatment effects that are limited to one sex may not have been detected. However, a strength of the pooling approach is the ability to sample multiple placentas from each dam, despite the cost limitations of the array approach.

Overall, the results of this study show that the mouse placenta can recover normal morphology and gene expression by term despite early growth restriction resulting from maternal nutrient restriction in early pregnancy. While there were still differences in fetal liver gene expression at d18.5, further study is needed to identify their physiological significance. It has been proposed in the DOHAD field that the mechanism by which maternal nutrient restriction in early pregnancy influences adult health is via permanent alterations in the placenta. It was the goal of this series of studies to better understand that mechanism. By exposing dams to early pregnancy nutrient restriction, then examining the placenta at mid- and late pregnancy, we would identify the lasting changes in gene expression and placental morphology that underlie programming of the adult. Instead, we encountered an unexpected phenomenon; early placental changes were reversible, and the offspring were normal. Additional studies are needed to uncover mechanisms by which the placenta is able to recover and protect the fetus from permanent damage.

\section{Supplementary data}

This is linked to the online version of the paper at http://dx.doi. org/10.1530/REP-15-0010.

\section{Declaration of interest}

The authors declare that there is no conflict of interest that could be perceived as prejudicing the impartiality of the research reported.

\section{Funding}

This work was supported by grant number HD055231 from the Eunice Kennedy Shriver National Institute of Child Health \& Human Development.

\section{Acknowledgements}

Thanks to Jessica Schlitt and Lisa Mao for technical assistance.

\section{References}

Anderson N \& Borlak J 2008 Molecular mechanisms and therapeutic targets in steatosis and steatohepatitis. Pharmacological Reviews 60 311-357. (doi:10.1124/pr.108.00001)

Anguita RM, Sigulem DM \& Sawaya AL 1993 Intrauterine food restriction is associated with obesity in young rats. Journal of Nutrition 123 1421-1428.

Barker DJ, Bull AR, Osmond C \& Simmonds SJ 1990 Fetal and placental size and risk of hypertension in adult life. BMJ 301 259-262. (doi:10. 1136/bmj.301.6746.259)

Barker DJ, Gelow J, Thornburg K, Osmond C, Kajantie E \& Eriksson JG 2010 The early origins of chronic heart failure: impaired placental growth and initiation of insulin resistance in childhood. European Journal of Heart Failure 12 819-825. (doi:10.1093/eurjhf/hfq069)

Bolstad BM, Irizarry RA, Astrand M \& Speed TP 2003 A comparison of normalization methods for high density oligonucleotide array data based on variance and bias. Bioinformatics 19 185-193. (doi:10.1093/ bioinformatics/19.2.185)

Bourgon R, Gentleman R \& Huber W 2010 Independent filtering increases detection power for high-throughput experiments. PNAS $\mathbf{1 0 7}$ 9546-9551. (doi:10.1073/pnas.0914005107)

Bruce KD, Cagampang FR, Argenton M, Zhang J, Ethirajan PL, Burdge GC, Bateman AC, Clough GF, Poston L, Hanson MA et al. 2009 Maternal high-fat feeding primes steatohepatitis in adult mice offspring, involving mitochondrial dysfunction and altered lipogenesis gene expression. Hepatology 50 1796-1808. (doi:10.1002/hep.23205)

Cifuentes D, Martinez-Pons C, Garcia-Rocha M, Galina A, Ribas de Pouplana L \& Guinovart J 2008 Hepatic glycogen synthesis in the absence of glucokinase: the case of embryonic liver. Journal of Biological Chemistry 283 5642-5649. (doi:10.1074/jbc.M706334200)

Clarke L, Heasman L, Juniper DT \& Symonds ME 1998 Maternal nutrition in early-mid gestation and placental size in sheep. British Journal of Nutrition 79 359-364. (doi:10.1079/BJN19980060)

Cox LA, Li C, Glenn JP, Lange K, Spradling KD, Nathanielsz PW \& Jansson T 2013 Expression of the placental transcriptome in maternal nutrient reduction in baboons is dependent on fetal sex. Journal of Nutrition 143 1698-1708. (doi:10.3945/jn.112.172148)

Dandrea J, Wilson V, Gopalakrishnan G, Heasman L, Budge H, Stephenson T \& Symonds ME 2001 Maternal nutritional manipulation of placental growth and glucose transporter 1 (GLUT-1) abundance in sheep. Reproduction 122 793-800. (doi:10.1530/rep.0.1220793)

Foote WC, Pope AL, Chapman AB \& Casida LE 1959 Reproduction in the yearling ewe as affected by breed and sequence of feeding levels. II. Effects on fetal development. Journal of Animal Science 18 463-474.

Ford SP, Hess BW, Schwope MM, Nijland MJ, Gilbert JS, Vonnahme KA, Means WJ, Han H \& Nathanielsz PW 2007 Maternal undernutrition during early to mid-gestation in the ewe results in altered growth, adiposity, and glucose tolerance in male offspring. Journal of Animal Science 85 1285-1294. (doi:10.2527/jas.2005-624)

Gardner DS, Tingey K, Van Bon BW, Ozanne SE, Wilson V, Dandrea J, Keisler DH, Stephenson T \& Symonds ME 2005 Programming of glucoseinsulin metabolism in adult sheep after maternal undernutrition. American Journal of Physiology. Regulatory, Integrative and Comparative Physiology 289 R947-R954. (doi:10.1152/ajpregu.00120.2005)

Gentleman RC, Carey VJ, Bates DM, Bolstad B, Dettling M, Dudoit S, Ellis B, Gautier L, Ge Y, Gentry J et al. 2004 Bioconductor: open software development for computational biology and bioinformatics. Genome Biology 5 R80. (doi:10.1186/gb-2004-5-10-r80)

Gentleman R, Carey V, Huber W, Irizarry R, Dudoit S 2005 Bioinformatics and Computational Biology Solutions using $R$ and Bioconductor, New York, NY: Springer.

Gluckman PD, Lillycrop KA, Vickers MH, Pleasants AB, Phillips ES, Beedle AS, Burdge GC \& Hanson MA 2007 Metabolic plasticity during mammalian development is directionally dependent on early nutritional status. PNAS 104 12796-12800. (doi:10.1073/pnas.0705667104) 
Greco D, Kotronen A, Westerbacka J, Puig O, Arkkila P, Kiviluoto T, Laitinen S, Kolak M, Fisher RM, Hamsten A et al. 2008 Gene expression in human NAFLD. American Journal of Physiology. Gastrointestinal and Liver Physiology 294 G1281-G1287. (doi:10.1152/ajpgi.00074.2008)

Gregorio BM, Souza-Mello V, Carvalho JJ, Mandarim-de-Lacerda CA \& Aguila MB 2010 Maternal high-fat intake predisposes non-alcoholic fatty liver disease in C57BL/6 offspring. American Journal of Obstetrics and Gynecology 203 495.e1-e8. (doi:10.1016/j.ajog.2010.06.042)

Jones AP \& Friedman MI 1982 Obesity and adipocyte abnormalities in offspring of rats undernourished during pregnancy. Science $\mathbf{2 1 5}$ 1518-1519. (doi:10.1126/science.7063860)

Jones AP, Simson EL \& Friedman MI 1984 Gestational undernutrition and the development of obesity in rats. Journal of Nutrition 114 1484-1492.

Koonen DP, Jacobs RL, Febbraio M, Young ME, Soltys CL, Ong H, Vance DE \& Dyck JR 2007 Increased hepatic CD36 expression contributes to dyslipidemia associated with diet-induced obesity. Diabetes $\mathbf{5 6}$ 2863-2871. (doi:10.2337/db07-0907)

Lemoine M, Barbu V, Girard PM, Kim M, Bastard JP, Wendum D, Paye F, Housset C, Capeau J \& Serfaty L 2006 Altered hepatic expression of SREBP-1 and PPAR $\gamma$ is associated with liver injury in insulin-resistant lipodystrophic HIV-infected patients. AIDS 20 387-395. (doi:10.1097/ 01.aids.0000206503.01536.11)

Lillycrop KA, Phillips ES, Jackson AA, Hanson MA \& Burdge GC 2005 Dietary protein restriction of pregnant rats induces and folic acid supplementation prevents epigenetic modification of hepatic gene expression in the offspring. Journal of Nutrition 135 1382-1386.

Livak KJ \& Schmittgen TD 2001 Analysis of relative gene expression data using real-time quantitative PCR and the $2(-\Delta \Delta C(\mathrm{~T}))$ Method. Methods 25 402-408. (doi:10.1006/meth.2001.1262)

Lumey LH 1998 Compensatory placental growth after restricted maternal nutrition in early pregnancy. Placenta 19 105-111. (doi:10.1016/S01434004(98)90105-9)

Ma Y, Xia W, Wang DQ, Wan YJ, Xu B, Chen X, Li YY \& Xu SQ 2013 Hepatic DNA methylation modifications in early development of rats resulting from perinatal BPA exposure contribute to insulin resistance in adulthood. Diabetologia 56 2059-2067. (doi:10.1007/s00125-013-2944-7)

Mao J, Zhang X, Sieli PT, Falduto MT, Torres KE \& Rosenfeld CS 2010 Contrasting effects of different maternal diets on sexually dimorphic gene expression in the murine placenta. PNAS 107 5557-5562. (doi:10.1073/ pnas.1000440107)

Martinez N, White V, Kurtz M, Higa R, Capobianco E \& Jawerbaum A 2011 Activation of the nuclear receptor PPARalpha regulates lipid metabolism in foetal liver from diabetic rats: implications in diabetes-induced foetal overgrowth. Diabetes and Metabolism Research Reviews 27 35-46. (doi:10.1002/dmrr.1151)

Painter RC, Roseboom TJ \& Bleker OP 2005 Prenatal exposure to the Dutch famine and disease in later life: an overview. Reproductive Toxicology 20 345-352. (doi:10.1016/j.reprotox.2005.04.005)

Palou M, Priego T, Sanchez J, Palou A \& Pico C 2010 Sexual dimorphism in the lasting effects of moderate caloric restriction during gestation on energy homeostasis in rats is related with fetal programming of insulin and leptin resistance. Nutrition \& Metabolism 7 69. (doi:10.1186/1743-7075-7-69)

Pennington KA, Harper JL, Sigafoos AN, Beffa LM, Carleton SM, Phillips CL \& Schulz LC 2012 Effect of food restriction and leptin supplementation on fetal programming in mice. Endocrinology 153 4556-4567. (doi:10. 1210/en.2012-1119)

Ravelli GP, Stein ZA \& Susser MW 1976 Obesity in young men after famine exposure in utero and early infancy. New England Journal of Medicine 295 349-353.
Rennie MY, Detmar J, Whiteley KJ, Jurisicova A, Adamson SL \& Sled JG 2012 Expansion of the fetoplacental vasculature in late gestation is strain dependent in mice. American Journal of Physiology. Heart and Circulatory Physiology 302 H1261-H1273. (doi:10.1152/ajpheart.00776.2011)

Roseboom T, de Rooij S \& Painter R 2006 The Dutch famine and its longterm consequences for adult health. Early Human Development $\mathbf{8 2}$ 485-491. (doi:10.1016/j.earlhumdev.2006.07.001)

Sardinha FL, Telles MM, Albuquerque KT, Oyama LM, Guimaraes PA, Santos OF \& Ribeiro EB 2006 Gender difference in the effect of intrauterine malnutrition on the central anorexigenic action of insulin in adult rats. Nutrition 22 1152-1161. (doi:10.1016/j.nut.2006.07.002)

Schulz LC, Schlitt JM, Caesar G \& Pennington KA 2012 Leptin and the placental response to maternal food restriction during early pregnancy in mice. Biology of Reproduction 87. (doi:10.1095/biolreprod.112.10321)

Sferruzzi-Perri AN, Vaughan OR, Coan PM, Suciu MC, Darbyshire R, Constancia M, Burton GJ \& Fowden AL 2011 Placental-specific Igf2 deficiency alters developmental adaptations to undernutrition in mice. Endocrinology 152 3202-3212. (doi:10.1210/en.2011-0240)

Shields BM, Freathy RM \& Hattersley AT 2010 Genetic influences on the association between fetal growth and susceptibility to type 2 diabetes. Journal of Developmental Origins of Health and Disease 1 96-105. (doi:10.1017/S2040174410000127)

Shimomura I, Bashmakov Y \& Horton JD 1999 Increased levels of nuclear SREBP-1c associated with fatty livers in two mouse models of diabetes mellitus. Journal of Biological Chemistry 274 30028-30032. (doi:10. 1074/jbc.274.42.30028)

Sinclair KD, Allegrucci C, Singh R, Gardner DS, Sebastian S, Bispham J, Thurston A, Huntley JF, Rees WD, Maloney CA et al. 2007 DNA methylation, insulin resistance, and blood pressure in offspring determined by maternal periconceptional B vitamin and methionine status. PNAS 104 19351-19356. (doi:10.1073/pnas.0707258104)

Smyth GK 2004 Linear models and empirical bayes methods for assessing differential expression in microarray experiments. Statistical Applications in Genetics and Molecular Biology 3 1-25. (doi:10.2202/1544-6115. 1027)

Terauchi Y, Kubota N, Tamemoto H, Sakura H, Nagai R, Akanuma Y, Kimura S \& Kadowaki T 2000 Insulin effect during embryogenesis determines fetal growth: a possible molecular link between birth weight and susceptibility to type 2 diabetes. Diabetes 49 82-86. (doi:10.2337/ diabetes.49.1.82)

Townsend KL, Lorenzi MM \& Widmaier EP 2008 High-fat diet-induced changes in body mass and hypothalamic gene expression in wild-type and leptindeficient mice. Endocrine 33 176-188. (doi:10.1007/s12020-008-9070-1)

Wang R, Gao H, Xu W, Li H, Mao Y, Wang Y, Guo T, Wang X, Song R, Li Z et al. 2013 Differential expression of genes and changes in glucose metabolism in the liver of liver-specific glucokinase gene knockout mice. Gene 516 248-254. (doi:10.1016/j.gene.2012.12.036)

Zhang J, Wang C, Terroni PL, Cagampang FR, Hanson M \& Byrne CD 2005 High-unsaturated-fat, high-protein, and low-carbohydrate diet during pregnancy and lactation modulates hepatic lipid metabolism in female adult offspring. American Journal of Physiology. Regulatory, Integrative and Comparative Physiology 288 R112-R118. (doi:10.1152/ajpregu. 00351.2004)

Received 28 January 2015

First decision 5 March 2015

Revised manuscript received 4 June 2015

Accepted 9 June 2015 